\title{
A Cyclic AMP-Dependent Form of Associative Synaptic Plasticity Induced by Coactivation of $\beta$-Adrenergic Receptors and Metabotropic Glutamate Receptors in Rat Hippocampus
}

\author{
Robert W. Gereau IV and P. Jeffrey Conn \\ Department of Pharmacology and Program in Neuroscience, Emory University School of Medicine, Atlanta, Georgia 30322
}

Recent studies suggest that increases in intracellular CAMP increase evoked synaptic responses in area CA1 of the hippocampus. We recently reported that activation of metabotropic glutamate receptors (mGluRs) in hippocampal slices potentiates CAMP responses to activation of other receptors that are positively coupled to adenylyl cyclase through Gs. It is possible that by enhancing CAMP responses, mGluRs could markedly potentiate the ability of agonists of Gs-coupled receptors to potentiate synaptic responses in area CA1. Such synergistic activation of a second messenger system could be involved in an associative form of neuronal plasticity in which simultaneous activation of two independent inputs to a cell is required for induction of a given change in synaptic transmission or neuronal excitability. We therefore tested the hypothesis that coactivation of mGluRs and a Gs-coupled receptor (the $\beta$-adrenergic receptor) could lead to large increases in CAMP accumulation in hippocampus and thereby increase synaptic responses in area $\mathrm{CA1}$. We report that coactivation of mGluRs and $\beta$-adrenergic receptors leads to a lasting (>30 min) increase in the amplitude of evoked population spikes at the Schaffer collateral-CA1 synapse. This effect is not accompanied by an increase in excitatory postsynaptic currents or by a decrease in synaptic inhibition in area CA1, suggesting that it is not mediated by a lasting change in excitatory or inhibitory synaptic transmission. However, coactivation of these receptors leads to a persistent depolarization of CA1 pyramidal cells with a concomitant increase in input resistance. Furthermore, coactivation of these receptors induces a lasting decrease in a slow afterhyperpolarization that follows a burst of action potentials in these cells and a lasting decrease in spike frequency adaptation. These electrophysiological effects are blocked by the protein kinase inhibitor staurosporine. Biochemical data suggest that the persistent increase in excitability of these cells is not mediated by a lasting increase in CAMP production. Taken together with previous reports demonstrating that CAMP analogs and the adenylyl cyclase activator forskolin mimic these effects, these data suggest that the response to coactivation of

Received June 30, 1993; revised Oct. 25, 1993; accepted Nov. 17, 1993.

This work was supported by NIH Grants NS-28405 and NS-31373 and grants from the Emory University Research Council and the Council for Tobacco Research. R.W.G. is a predoctoral fellow of the Howard Hughes Medical Institute. Correspondence should be addressed to P. Jeffrey Conn, Ph.D., Department of Pharmacology, Rollins Research Building, Emory University School of Medicine, Atlanta, GA 30322.

Copyright (C) 1994 Society for Neuroscience $0270-6474 / 94 / 143310-09 \$ 05.00 / 0$
mGluRs and $\beta$-adrenergic receptors is mediated by formation of CAMP and activation of CAMP-dependent protein kinase. This may represent a novel mechanism for an associative form of synaptic plasticity in the mammalian brain.

[Key words: metabotropic glutamate receptor, synaptic plasticity, norepinephrine, excitatory amino acid, protein kinase, adenylyl cyclase, CAMP, 1-aminocyclopentane-1,3-dicarboxylic acid (ACPD)]

Associative forms of learning are thought to involve the induction of long-lasting changes in neuronal excitability or synaptic function by simultaneous activation of two independent inputs to a cell. The most extensively studied form of synaptic plasticity in mammalian brain is long-term potentiation (LTP) of synaptic efficacy in the hippocampus (see Bliss and Collingridge, 1993, for review). The cellular mechanisms that underlie associativity of LTP have been well characterized and involve associative activation of the NMDA subtypc of glutamate receptors. However, little is known about the cellular mechanisms of NMDA receptor-independent forms of associative synaptic plasticity.

Metabotropic glutamate receptors (mGluRs) are coupled to a variety of effector systems via GTP-binding proteins (see Schoepp and Conn, 1993, for review). We recently demonstrated that activation of a novel $\mathrm{mGluR}$ in hippocampus markedly potentiates cAMP responses to agonists of receptors that are positively coupled to adenylyl cyclase via Gs (Winder and Conn, 1992, 1993). This mGluR subtype is clearly distinct from the major phosphoinositide hydrolysis-linked mGluR in hippocampal slices (Winder et al., 1993) and appears to belong to a growing family of receptors that interact synergistically with Gscoupled receptors to increase cAMP accumulation (Magistretti and Schorderet, 1985; Pilc and Enna, 1986; Johnson and Minneman, 1987; Garbarg and Schwartz, 1988; Schaad et al., 1989). At present, the physiological roles of this mGluR subtype are not known. However, recent studies indicate that increases in intracellular cAMP can induce lasting changes in synaptic responses in the hippocampal formation (Heginbotham and Dunwiddie, 1991; Slack and Pockett, 1991; Chavez-Noriega and Stevens, 1992; Dunwiddie et al., 1992; Haas and Gahwiler, 1992). We report that activation of mGluRs can potentiate $\beta$-adrenergic receptor-mediated increases in CAMP accumulation in hippocampal slices and that coactivation of $m$ GluRs and $\beta$-adrenergic receptors induces a lasting enhancement of evoked population spikes in hippocampal area CA1. A similar enhancement of evoked population spikes is observed in hippocampal LTP. However, the response described here is clearly distinct from LTP in that it is mediated by an increase in excitability of CA 1 
pyramidal cells rather than an increase in transmission at the Schaffer collateral-CAl synapse. This long-lasting change in synaptic function induced by simultaneous activation of receptors for two independent neurotransmitters could provide a novel.mechanism for an associative form of synaptic plasticity in the hippocampus.

\section{Materials and Methods}

Materials. All drugs were obtained from Sigma (St. Louis, MO) except 1 -aminocyclopentane-1 $S, 3 S$-dicarboxylic acid (1S,3S-ACPD), which was obtained from Tocris Neuramin (Essex, UK).

Measurement of cyclic AMP (cAMP) accumulation in hippocampal slices. CAMP accumulation was determined using a modification of the method of Shimizu et al. (1969) as described by Johnson and Minneman (1986). Briefly, adult male Sprague-Dawley rats (120-250 gm) were killed by rapid decapitation, and the brains were removed and placed in ice-cold Krebs Ringer bicarbonate buffer (KRB) for approximately $1 \mathrm{~min}$. Hippocampi were dissected on ice and cross-chopped slices (350 $\mu \mathrm{m} \times 350 \mu \mathrm{m})$ were prepared using a McIlwain tissue chopper. Following a $15 \mathrm{~min}$ incubation in $\mathrm{KRB}$ at $37^{\circ} \mathrm{C}$, the tissue was washed with $\mathrm{KRB}$ and incubated for $40 \mathrm{~min}$ in $\mathrm{KRB}$ containing $9 \mu \mathrm{M}$ unlabeled adenine and $30 \mu \mathrm{Ci}$ of ${ }^{3} \mathrm{H}$-adenine (American Radiolabelled Chemicals, St. Louis, MO). All incubations were carried out under an atmosphere of $95 \% \mathrm{O}_{2}, 5 \% \mathrm{CO}_{2}$. The tissue was then rinsed several times with $\mathrm{KRB}$ and gravity packed. Twenty-five microliter aliquots of gravity packed slices were placed in $10 \mathrm{ml}$ test tubes containing appropriate drugs to a final volume of $500 \mu 1$, and incubated for $15 \mathrm{~min}$ at $37^{\circ} \mathrm{C}$. The reaction was stopped by addition of $50 \mu \mathrm{l}$ of $77 \%$ trichloroacetic acid with $25 \mu \mathrm{l}$ of $10 \mathrm{~mm}$ cAMP added as a carrier. The tissue was homogenized and centrifuged for $15 \mathrm{~min}$ at $37,000 \times \mathrm{g}$. Twenty-five microliter aliquots of the supernatant were removed for determination of total ${ }^{3} \mathrm{H}$-adenine incorporation, and the remaining supernatant was sequentially eluted over Dowex and Alumina columns for isolation of cAMP. Radioactivity was determined using a liquid scintillation counter. $\mathrm{KRB}$ contained (in mм) $\mathrm{NaCl}, 108 ; \mathrm{KCl} 4.7 ; \mathrm{CaCl}_{2}, 2.5 ; \mathrm{MgSO}_{4}, 1.2 ; \mathrm{KH}_{2} \mathrm{PO}_{4}, 1.2 ;$ glucose, 10 ; and $\mathrm{NaHCO}_{3}, 25 ; \mathrm{pH} 7.4$.

The same protocol was used for experiments testing the time course of cAMP increases with the following exceptions. First, agonist incubations were carried out for only $10 \mathrm{~min}$ in order to mimic the conditions of our physiological recordings. In one experimental group, hippocampal slices were incubated in the presence of agonists for $10 \mathrm{~min}$, at which point the reaction was terminated by the addition of trichloroacetic acid. In a second group, the slices were incubated in agonist for $10 \mathrm{~min}$, after which the drugs were removed by dilution into $10 \mathrm{ml}$ of $\mathrm{KRB}$ (the excess was removed to return the final volume to $500 \mu \mathrm{l}$ ), and the slices were incubated for a further $30 \mathrm{~min}$ in $\mathrm{KRB}$. In the final experimental group, slices were incubated in the presence of agonists for the full 40 min of the experiment, at which point the reaction was terminated.

Electrophysiological recordings. The hippocampus was dissected as above and $400 \mu \mathrm{m}$ transverse slices were prepared and placed into oxygenated artificial cerebrospinal fluid (ACSF) containing (in $\mathrm{mM}$ ) $\mathrm{NaCl}$, $124 ; \mathrm{KCl}, 2.5 ; \mathrm{CaCl}_{2}, 2 ; \mathrm{MgSO}_{4}, 1.3 ; \mathrm{NaH}_{2} \mathrm{PO}_{4}, 1 ;$ glucose, 10 ; and $\mathrm{NaHCO}_{3}, 26$; equilibrated to $\mathrm{pH} 7.4$ with $95 \% \mathrm{O}_{2}, 5 \% \mathrm{CO}_{2}$. After a 1 $\mathrm{hr}$ recovery period, a slice was transferred to a submerged brain slice recording chamber, where it was continuously perfused with warmed $\left(30^{\circ} \mathrm{C}\right)$ oxygenated ACSF at $1 \mathrm{ml} / \mathrm{min}$. Drugs were applied for $10 \mathrm{~min}$ and delivered through the perfusion medium.

For recording of population spikes and field excitatory postsynaptic potentials (fEPSPs), recording electrodes were placed in stratum pyramidale and stratum radiatum of area $\mathrm{CA1}$, respectively. All electrodes were pulled on a Flaming Brown electrode puller (Sutter Instruments, San Rafael, CA) from $1.2 \mathrm{~mm}$ borosilicate glass (World Precision Instruments, Sarasota, FL). Extracellular electrodes were pulled to a resistance of $1-5 \mathrm{M} \Omega$ with a filling solution of $2 \mathrm{M} \mathrm{NaCl}$. A bipolar tungsten stimulating electrode was placed in stratum radiatum of area $\mathrm{CA} 1$ for stimulation $(0.1 \mathrm{msec})$ of Schaffer collateral afferents. The stimulus intensity was adjusted until field potential responses to afferent stimulation were less than $50 \%$ of the maximal response.

Intracellular recordings were made from CA1 pyramidal neurons using sharp microelectrodes filled with $3 \mathrm{M} \mathrm{KCl}$ (resistance, 70-120 M $\Omega$ ), except for recording of inhibitory postsynaptic potentials (IPSPs), for which electrodes were filled with 2 M potassium methylsulfate $(K \& K$ Laboratories, Cleveland, $\mathrm{OH})$. Electrodes were placed in stratum pyramidale under visual guidance and then small $(2.5-5 \mu \mathrm{m})$ steps were made with a hydraulic drive (David Kopf Instruments, Tujunga, CA). Cell penetration was accomplished by brief $(0.2 \mathrm{msec})$ overutilization of capacitance compensation. Only cells with an input resistance of $\geq 70$ $\mathrm{M} \Omega, V_{m}$ more negative than $-55 \mathrm{mV}$, and a slow afterhyperpolarization (AHP) amplitude of $\geq 5 \mathrm{mV}$ were used, and only preparations with stable baseline responses were included in these studies. AHPs were elicited by brief $(80 \mathrm{msec})$ depolarizing current injection through the recording electrode $(0.4 \mathrm{nA})$. Spike frequency adaptation was evaluated by measuring the membrane voltage response to prolonged $(800 \mathrm{msec})$ depolarizing current injection $(0.2-0.3 \mathrm{nA})$. Input resistancc was determined by measuring the voltage response to $200 \mathrm{msec}$ hyperpolarizing current injection $(-0.3 \mathrm{nA})$ and applying Ohm's law. Polysynaptic IPSPs were elicited in area CA1 by $0.1 \mathrm{msec}$ stimulation of Schaffer collateral afferents and the stimulus intensity was adjusted until the IPSP was approximately $50 \%$ of the maximal response. During measurements of the AHP, spike trequency adaptation, and IPSPs, the cell's resting potential was maintained at the original resting potential by injection of DC current.

Whole-cell patch-clamp recordings were made from CAl pyramidal cells using a Warner Instrument Corp. (Hamden, CT) patch-clamp model PC-501A. The blind patch-clamp technique was used as described (Blanton et al., 1989). Patch electrodes were fabricated from borosilicate glass (World Precision Instruments, Sarasota, FL) to a resistance of 3$7 \mathrm{M} \Omega$ with a filling solution that contained (in $\mathrm{mM}$ ) HEPES, 40; gluconic acid, 100; EGTA, 0.6; GTP, 0.3; ATP, 2; $\mathrm{MgCl}_{2}, 5 ; \mathrm{pH}$ to 7.4 with $50 \%$ $\mathrm{CsOH}$. Series resistance was monitored, and cells exhibiting series resistances of $>25 \mathrm{M} \Omega$ were discarded. For patch-clamp recordings, the bathing ACSF was as above, except that it contained $100 \mu \mathrm{M}$ picrotoxin (Sigma, St. Louis, MO), and the Schaffer collateral pathway was cut at the CA3/CAl border to eliminate recurrent excitatory circuits. Stimuli were delivered to the Schaffer collaterals as described above. Care was taken to evoke low-amplitude ( $\leq 100 \mathrm{pA}$ ) excitatory postsynaptic currents (EPSCs) in order to minimize errors due to series resistance, and voltage clamp was periodically evaluated by determining the reversal potential of evoked currents.

Field potential and intracellular recordings were made using an Axoclamp 2A (Axon Instruments, Foster City, CA) in bridge mode, and data were digitized and stored on videotape using a Neurocorder model DR-384 (NeuroData, New York, NY). Data were analyzed using pCLAMP data acquisition and analysis software (Axon instruments).

\section{Results}

In designing studies aimed at determining the physiological actions of the mGluR that potentiates cAMP responses, it was necessary to address several potential problems that arise from the use of ACPD as an mGluR agonist. First, both trans-ACPD and $1 S, 3 R$-ACPD have been shown to cause depression of synaptic transmission in area CA1 (Baskys and Malenka, 1991; Desai et al., 1992), an effect that could obfuscate an increase in population spikes in response to activation of these receptors. However, we have previously shown that $100 \mu \mathrm{M} 1 S, 3 S$-ACPD does not decrease transmission in area CAl of slices from adult animals (Desai et al., 1992). In addition, 1S,3S-ACPD and $1 S, 3 R$-ACPD have becn shown to be equally effective at potentiating cAMP responses in hippocampus (Winder and Conn, 1992; Winder et al., 1993). Therefore, we performed our experiments utilizing $1 S, 3 S$-ACPD to avoid the depression of synaptic transmission that can be induced by this concentration of $1 S, 3 R$-ACPD. Another potential problem arises from studies reporting that $20 \mathrm{~min}$ applications of $10 \mu \mathrm{M} 1 S, 3 R-A C P D$ induces LTP in area CA 1 of the rat hippocampus (Bortolotto and Collingridge, 1992; Bashir et al., 1993). However, this effect appears to occur only under certain conditions, and shorter applications of 50-100 $\mu \mathrm{M} 1 S, 3 S$-ACPD or $1 S, 3 R$-ACPD fail to induce any lasting changes in synaptic transmission in area CA1 (Desai and Conn, 1991; Baskys and Malenka 1991; Otani and Ben-Ari, 1991; Desai et al., 1992; Collins and Davies, 1993). Thus, we performed these experiments under conditions in which $1 S, 3 S$-ACPD does not induce LTP. 


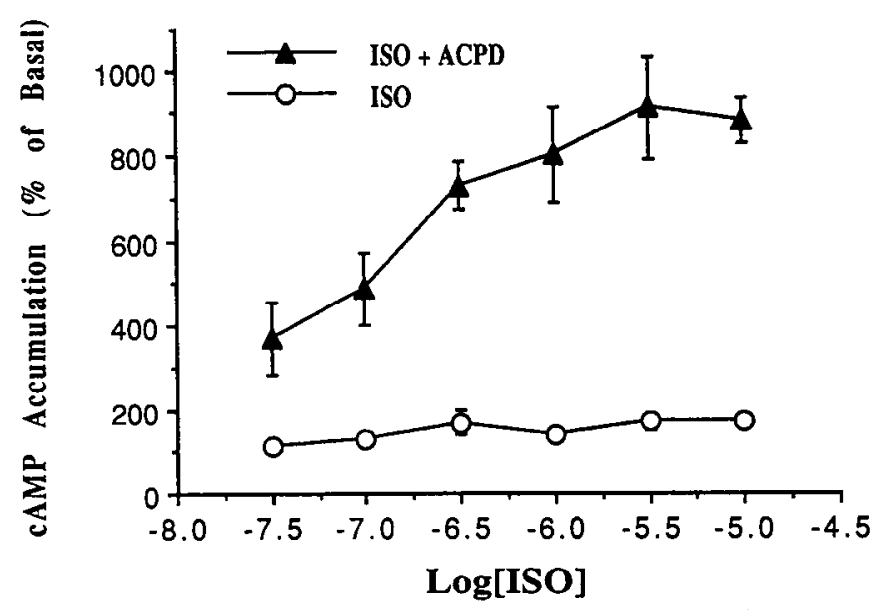

Figure 1. IS 3.S-ACPD potentiates ISO-induced cAMP accumulation in hippocampal slices. The effect of increasing concentrations of ISO was determined in the presence and absence of $100 \mu \mathrm{M} 1 S, 3 S$-ACPD. c $\triangle M P$ accumulation was determined by measuring conversion of ${ }^{3} \mathrm{H}$ adenine to ${ }^{3} \mathrm{H}$-cAMP. Data are presented as percentage of basal cAMP accumulation in the absence of added agonist $(15 \mathrm{~min}$ agonist incubation). Basal values were $0.25 \perp 0.03 \%$ conversion of incorporatcd ${ }^{3} \mathrm{H}$-adenine to ${ }^{3} \mathrm{H}$-cAMP. Each point represents the mean $\pm \mathrm{SEM}$ of three experiments, each done in triplicate.

\section{$1 \mathrm{~S}, 3 \mathrm{~S}-A C P D$ and isoproterenol act synergistically to increase cAMP accumulation in hippocampus}

Isoproterenol (ISO) and $1 S, 3 S$-ACPD were used as $\beta$-adrenergic and mGluK agonists, respectively. Previous studies suggest that $100 \mu \mathrm{M} 1 S, 3 S$-ACPD is a maximally effective concentration at potentiating cAMP responses to other agonists (Winder and Conn, 1992, 1993). The effect of $15 \mathrm{~min}$ incubations with increasing concentrations of ISO were measured in the absence and presence of $100 \mu \mathrm{M} 1 S, 3 S$-ACPD. Consistent with previous reports, ISO induced a slight concentration-dependent increase in cAMP accumulation in cross chopped hippocampal slices with a maximal response of approximately $170 \pm 9 \%$ of basal (Fig. 1). 1S,3S-ACPD $(100 \mu \mathrm{M})$ also induced a slight increase in cAMP accumulation when added alone (see Fig. 6) and markedly potentiated cAMP responses to each concentration of ISO tested (Fig. 1). The maximal cAMP response to ISO in the presence of $1 S, 3 S$-ACPD was $910 \pm 121 \%$ of basal.

Coactivation of $m G l u R s$ and $\beta$-adrenergic receptors causes a lasting potentiation of evoked population spikes in area CAI of the hippocampal formation

Scveral studies suggest that transient increases in cAMP in hippocampal area CA1 can lead to a persistent increase in popu- lation spike amplitude in this region (Heginbotham and Dunwiddie, 1991; Slack and Pockett, 1991; Chavez-Noriega and Stevens, 1992; Dunwiddie et al., 1992; Haas and Gahwiler, 1992). We tested the hypothesis that $\mathrm{mGluR}$ and $\beta$-adrenergic receptor activation could act synergistically to elicit this form of synaptic plasticity by examining the effect of ISO, $1 S, 3 S$ ACPD, and a combination of the two drugs on evoked population spikes at the Schaffer collateral-CA1 synapse. Previous studies indicate that ISO concentrations of $500 \mathrm{~nm}$ or greater, which elicits a maximal increase in cAMP accumulation (see Fig. 1), can elicit a lasting increase in population spike amplitude and CAl pyramidal cell excitability (Heginbotham and Dunwiddie, 1991; Dunwiddie et al., 1992). Thus, a concentration of ISO (100 $\mathrm{nm})$ that elicited a clearly submaximal increase in cAMP accumulation when added alone (Fig. 1) was used for these studies. Bath application of $100 \mathrm{~nm}$ ISO caused a transient increase in population spike amplitude during drug application that reversed within $30 \mathrm{~min}$ of drug washout (Fig. $2 ; n=6$ ). Application of $100 \mu \mathrm{M} 1 S, 3 S$-ACPD had similar effects (Fig. 2; $n=7$ ). In contrast, coapplication of these drugs elicited a transient increase in population spike amplitude followed by a depression of the population spike. This was followed by a longlasting increase in population spike amplitude that persisted for at least $30 \mathrm{~min}$ after washout of the drugs (Fig. 2, Table $1 ; p<$ 0.05 , paired $t$ test; $n=7$ ). This multiphasic response is virtually identical to the previously described response to $10 \mu \mathrm{M}$ forskolin (Dunwiddie et al., 1992) or cell-permeable cAMP analogs (Slack and Pockett, 1991; Dunwiddie et al., 1992). Furthermore, the long-lasting increase in population spike amplitude was completely blocked in the presence of the protein kinase inhibitor staurosporine (Fig. 2D, Table 1). The concentrations of staurosporine used (500 $\mathrm{nM}$ to $1 \mu \mathrm{M}$ ) are effective at inhibiting cAMPdependent protein kinase (Davis et al., 1989) but do not block mGluR-mediated potentiation of cAMP responses in hippocampus (Winder and Conn, 1993). Thus, the blockade of physiological responses to $I S O$ and $1 S, 3 S$-ACPD is likely due to protein kinase inhibition. These data suggest that the long-lasting increase in population spikc amplitude is mediated by formation of CAMP and activation of a protein kinase.

\section{The long-lasting enhancement of CAl population spikes is mediated by a persistent increase in excitability of $C A I$ pyramidal cells}

Although we do not know the mechanism by which ISO plus ACPD induces the transient depression of evoked population spikes, previous studies suggest that cAMP can both increase transmission at the Schaffer collateral-CA1 synapse (ChavezNoriega and Stevens, 1992; Haas and Gahwiler, 1992) and in-

Table 1. Effects of various agonist treatments on synaptic responses in area CA1
\begin{tabular}{lclll}
$\begin{array}{l}\text { Drug } \\
\text { treatment }\end{array}$ & PS amplitude & fEPSP slope & EPSC amplitude & IPSP amplitude \\
\hline ISO & $98.8 \pm 10.0(5)$ & $96.0 \pm 12.8(5)$ & $103.2 \pm 9.3(6)$ & ND \\
ACPD & $81.3 \pm 14.0(6)$ & $89.0 \pm 15.6(6)$ & $115.5 \pm 20.9(7)$ & ND \\
ISO + ACPD & $133.4 \pm 22.0(7)^{*}$ & $94.8 \pm 11.5(7)$ & $97.5 \pm 13.9(8)$ & $111.0 \pm 13.7(5)$ \\
ISO + ACPD & & & & ND \\
$\quad+$ STAUR & $87.3+9.6(5)$ & ND & ND
\end{tabular}

Values given represent the mean \pm SEM change in the synaptic response recorded 30 min after drug washout, expressed as percentage of predrug responses. Number of experiments in each group is given parenthetically. PS, population spike. ISO, $100 \mathrm{~nm}$; $1 S, 3 S$-ACPD, $100 \mu \mathrm{M}$; STAUR, staurosporine (500 nM). ND, not determined.

${ }^{*} p<0.05$, paired $t$ test. 


\section{$\mathbf{A}$ \\ Before \\ During \\ 30min Wash}

ISO

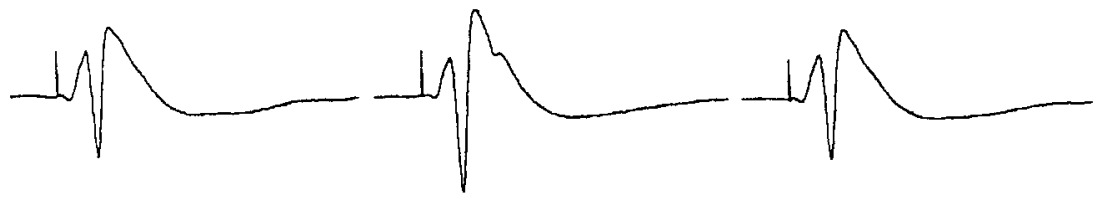

ACPD
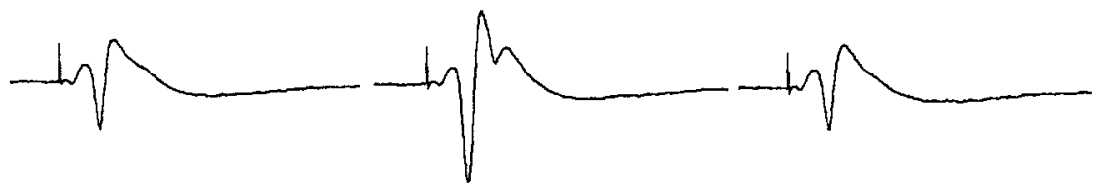

Figure 2. Coapplication of ISO and $1 S, 3 S$-ACPD induces a protein kinasedependent long-lasting increase in the amplitude of evoked population spikes in area CAl. $A$ shows evoked population spikes recorded before, during, and $30 \mathrm{~min}$ after washout of ISO (100 nM), $1 S, 3 S$-ACPD $(100 \mu \mathrm{M})$, or a combination of the two drugs. All traces shown are the averages of three traces recorded immediately before drug application, at the maximal potentiation during drug application, and $30 \mathrm{~min}$ after drug washout. Paired $t$ tests revealed that neither ISO $(p>0.05 ; n=6)$ nor $1 S, 3 S$ $\operatorname{ACPD}(p>0.05 ; n=7)$ alone induced a significant increase in population spike amplitude recorded $30 \mathrm{~min}$ after drug washout. In contrast, coapplication of ISO plus $1 S, 3 S$-ACPD induced a lasting enhancement of population spike amplitude that persisted for at least 30 min after washout of drugs $(p<0.05$; $n=7$ ). $B$ shows time course of effects of $100 \mathrm{~nm}$ ISO and $100 \mu \mathrm{M} 1 S, 3 S$-ACPD individually, and $C$ shows effects of coapplication of ISO and $1 S, 3 S$-ACPD on population spikes (PS) in representative slices. Each point represents the amplitude of an individual population spike elicited at $0.1 \mathrm{~Hz}$. $D$ shows population spike traces from an experiment in which $100 \mathrm{nM}$ ISO and $100 \mu \mathrm{M} 1 S, 3 S$ ACPD were coapplied to a slice in the presence of $500 \mathrm{~nm}$ staurosporine (present throughout the experiment). In slices treated with staurosporine, the mean population spike amplitude $30 \mathrm{~min}$ after treatment with ISO plus $1 S, 3 S$ ACPD was not significantly different from the population spike amplitude before drug treatment $(p>0.05 ; n=$ 5). Staurosporine (500 nM) alone had no effect on population spike amplitude or fepsp slope (data not shown).

crease excitability of CA1 pyramidal cells (Dunwiddie et al., 1992). The increase in population spike amplitude could be mediated by either of these mechanisms depending on the subcellular localization of the receptors involved. Coactivation of mGluRs and $\beta$-adrenergic receptors could also enhance evoked population spikes by inducing a lasting reduction of synaptic inhibition. Thus, we performed a series of studies to determine which of these mechanisms is involved in the synergistic potentiation of population spike amplitude.

Simultaneous recordings of population spikes and fEPSPs revealed that the increase in population spike amplitude was not associated with an increase in the initial slope of the fEPSP (Fig. $3 A ; p>0.05 ; n=7)$. Since field potentials can be reduced by a postsynaptic depolarization, we confirmed the lack of increase of the fEPSP by measuring EPSCs from CAl pyramidal cells using whole-cell patch clamp. These studies confirmed the data obtained with field potentials, as ISO plus $1 S, 3 S$-ACPD did not result in an increase in the amplitude of EPSCs (Fig. 3B, Table $1 ; p>0.05 ; n=8$ ).

Polysynaptic IPSPs were measured using intracellular recordings of responses of CA 1 pyramidal cells to stimulation of Schaffer collateral afferents (Fig. $3 C$ ). These IPSPs contained both $\mathrm{GABA}_{\mathrm{A}}$ and $\mathrm{GABA}_{\mathrm{B}}$ components. Although these components were often temporally overlapping and could not always be discerned visually, the use of selective $G_{A B A}$ and/or $G_{A B A}$ antagonists suggested that both components can be measured in virtually all pyramidal cells (data not shown). Coapplication of ISO (100 nM) and $1 S, 3 S$-ACPD $(100 \mu \mathrm{M})$ did not induce a persistent reduction of polysynaptic IPSPs (Fig. 3C, Table $1 ; p$ $>0.05 ; n=5$ ). These data suggest that these compounds are 

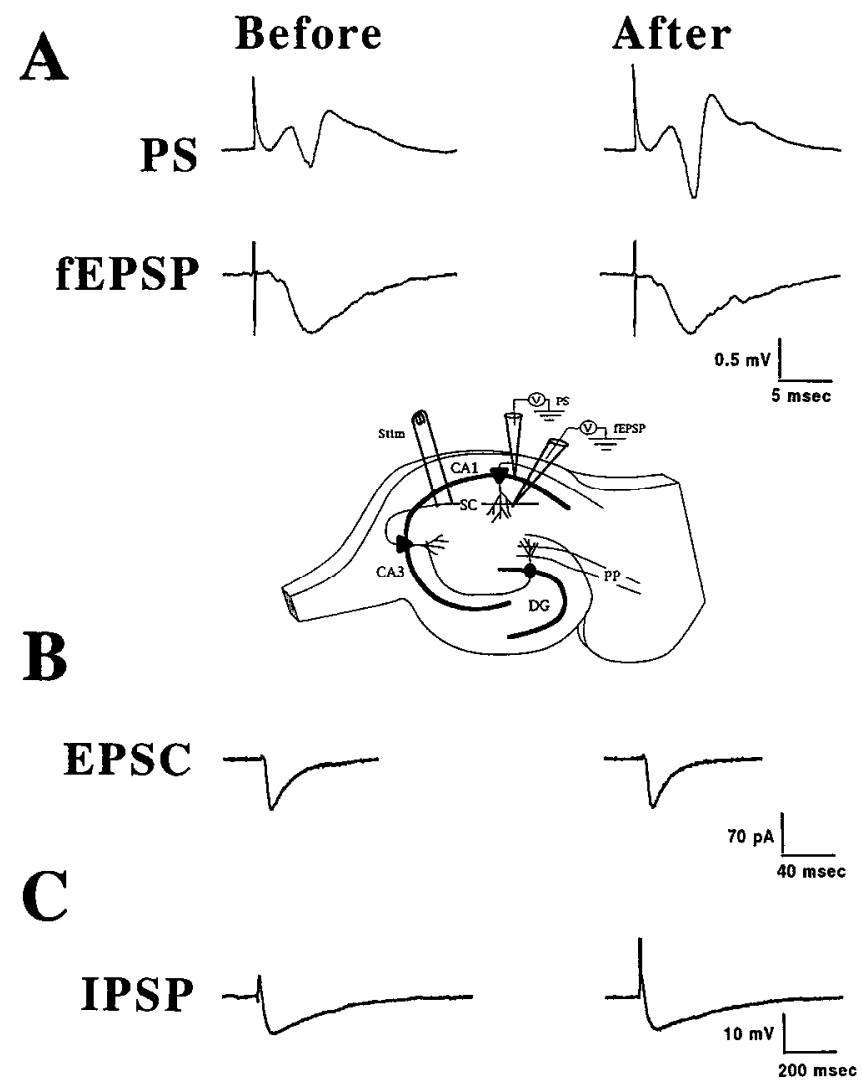

Figure 3. Enhancement of population spike amplitude induced by coapplication of ISO plus $1 S, 3 S$-ACPD is not accompanied by an increase in excitatory transmission at the Schaffer collateral-CA1 synapse or a decrease in synaptic inhibition in area CA1. Population spikes ( $P S)$ and $\mathrm{fEPSPs}$ were recorded simultaneously from stratum pyramidale and stratum radiatum, respectively, of area CA1. A shows representative traces recorded before and $30 \mathrm{~min}$ after washout of $100 \mathrm{nM}$ ISO plus $100 \mu \mathrm{M} 1 S, 3 S$-ACPD. The mean ( \pm SEM) fEPSP slope was $0.19 \pm 0.03$ $\mathrm{mV} / \mathrm{msec}$ for $\mathrm{fEPSPS}$ recorded prior to drug application and $0.18 \pm$ $0.02 \mathrm{mV} / \mathrm{msec}$ after a $30 \mathrm{~min}$ wash (paired $t$ test, $p>0.05 ; n=7$ ). The diagram shows electrode placement in hippocampal slices used for simultaneous recording of population spikes and fEPSPs. Stim, stimulating electrode; $D G$, dentate gyrus; $P P$, perforant path; $S C$, Schaffer collateral. $B$ shows the effect of ISO plus $1 S, 3 S$-ACPD on evoked EPSCs recorded in CAl pyramidal cells. Coactivation of these receptors did not result in a change in the amplitude of EPSCs (paired $t$ test, $p>$ $0.05 ; n=8$ ). $C$ shows the effect of ISO plus $1 S, 3 S$-ACPD on polysynaptic IPSPs recorded in CAl pyramidal cells. Coapplication of $100 \mathrm{nM}$ ISO plus $100 \mu_{\mathrm{M}} 1 S, 3 S$-ACPD did not induce a lasting change in the amplitude of IPSPs evoked by stimulation of Schaffer collateral afferents (paired $t$ test, $p>0.05 ; n=5$ ).

not likely to induce the long-lasting increase in population spike amplitude by either enhancing transmission at the Schaffer collateral-CA1 synapse or reducing synaptic inhibition in area CA1.

The finding that coapplication of ISO and $1 S, 3 S$-ACPD does not induce a lasting change in inhibitory or excitatory synaptic transmission suggests that these compounds must enhance population spikes by inducing a lasting enhancement of pyramidal cell excitability in a manner similar to that reported by Dunwiddie et al. (1992). Thus, the effect of these compounds on the membrane properties of CA1 pyramidal cells was evaluated. Consistent with previous reports (Desai et al., 1992; Dunwiddie et al., 1992) either $1 S, 3 S$-ACPD $(100 \mu \mathrm{M})$ or ISO $(30 \mathrm{nM})$ induced a transient depolarization of $\mathrm{C} \Lambda 1$ pyramidal cells with an accompanying increase in input resistance when added alone.

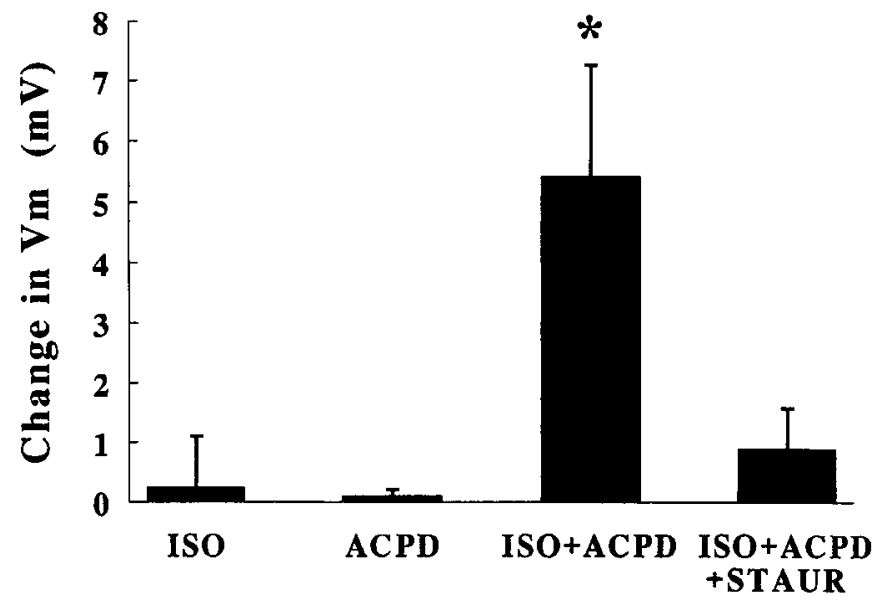

Figure 4. Coapplication of ISO and $1 S, 3 S$-ACPD induces a lasting depolarization of CA1 pyramidal cells that is dependent on protein kinase activation. Shown are the mean $( \pm$ SEM) changes in resting membrane potential $\left(V_{m}\right)$ of CAl pyramidal cells recorded 30 min after washout of $100 \mathrm{nM}$ ISO, $100 \mu \mathrm{M} 1 S, 3 S$-ACPD, or a combination of the two drugs (in the presence and absence of $1 \mu \mathrm{M}$ staurosporine, present throughout the experiment). ${ }^{*}, p<0.05$, paired $t$ test comparing mean observed $V_{m} 30$ min after drug washout with $V_{m}$ prior to drug addition $(n=5,6$, and 7 for ISO, $1 S, 3 S$-ACPD, and ISO plus $1 S, 3 S$-ACPD, respectively)

This effect was rapidly reversed when the drugs were washed from the slice and neither ISO nor $1 S, 3 S$-ACPD induced a lasting change in membrane potential (Fig. 4). However, coapplication of ISO $(30 \mathrm{~nm})$ and $1 S, 3 S-A C P D(100 \mu \mathrm{M})$ induced a persistent depolarization of CAl pyramidal cells that could be measured $30 \mathrm{~min}$ after washout of the drugs (Fig. 4). This depolarization was associated with a small but statistically significant increase in input resistance from $82.9 \pm 4.5 \mathrm{M} \Omega$ before drug application to $90.3 \pm 6 \mathrm{M} \Omega$ after washout of the drugs (paired $t$ test; $p<0.05, n=5$ ). As with the increase in population spike amplitude, the persistent depolarization of pyramidal cells was completely blocked by staurosporine (Fig. 4).

In addition to inducing a persistent depolarization of CAl pyramidal cells, coapplication of ISO plus $1 S, 3 S$-ACPD induced a persistent decrease in the amplitude of the slow AHP that follows a burst of action potentials (Fig. 5). The current that underlies the slow AHP is a calcium-dependent potassium current that is involved in limiting repetitive firing in CAl pyramidal cells, a process known as spike frequency adaptation (Madison and Nicoll, 1986). Accordingly, the decrease in AHP amplitude was always accompanied by a decrease in spike frequency adaptation (Fig. 5). The concentrations of ISO and $1 S, 3 S$ ACPD used in these experiments induced only transient changes in AHP amplitude and spike frequency adaptation when added alone. As with their effects on population spikes and membrane potential, the lasting reduction of the AHP and spike frequency adaptation were blocked by staurosporine (Fig. 5), suggesting that these effects are mediated by activation of a protein kinase.

Coactivation of $m G$ GuRs and $\beta$-adrenergic receptors does not result in a lasting increase in CAMP accumulation in hippocampus

One possible mechanism by which ISO $+1 S, 3 S$-ACPD could induce a lasting increase in population spike amplitude and CA 1 pyramidal cell excitability is by inducing a lasting increase in intracellular cAMP levels. Alternatively, a transient increase in 


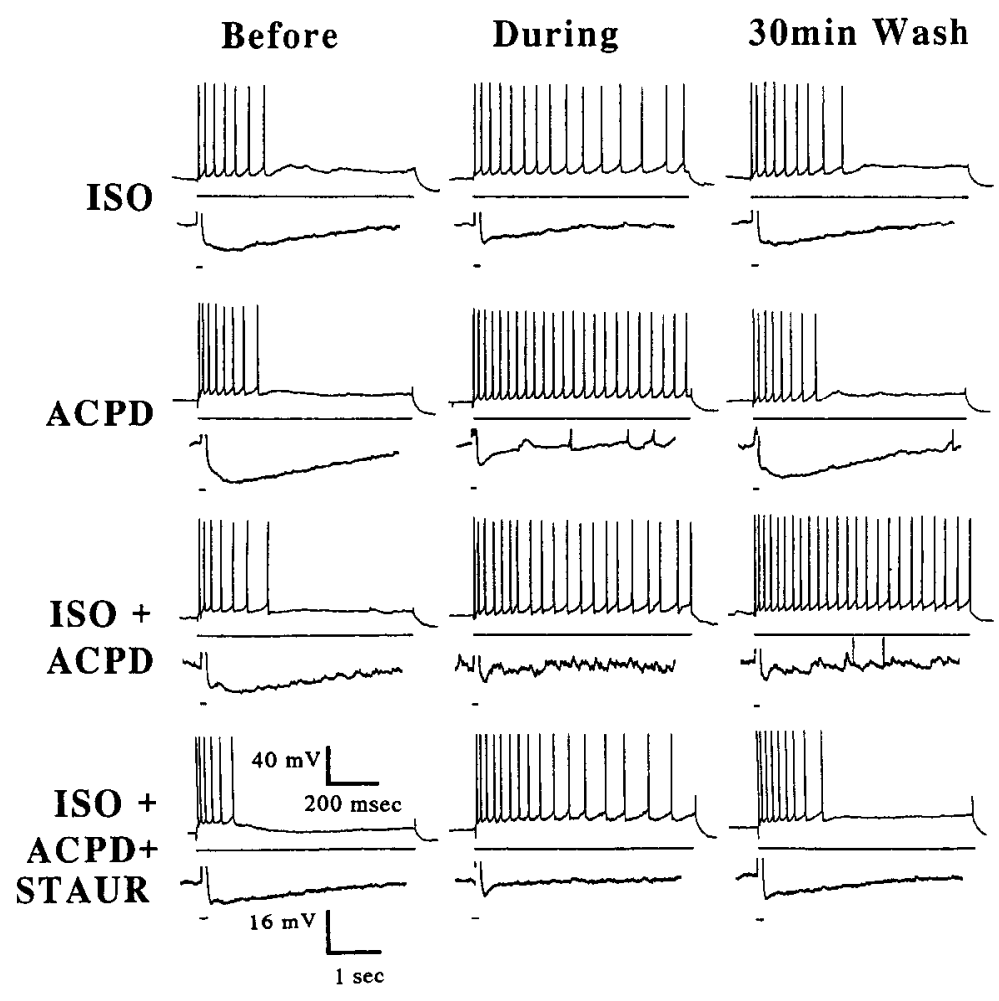

Figure 5. Coapplication of ISO plus $1 S, 3 S$-ACPD causes a long-lasting decrease in the slow AHP and spike frequency adaptation. The effect of ISO $(30 \mathrm{nM}), 1 S, 3 S-\mathrm{ACPD}(100 \mu \mathrm{M})$, and a combination of these drugs (in the presence and absence of $1 \mu \mathrm{M}$ staurosporine, present throughout the experiment) on spike frequency adaptation (top traces) and AHPs (bottom traces) is shown before drug application, during drug application, and at the maximal recovery observed during a $30 \mathrm{~min}$ wash. Periods of current injection are represented by the horizontal bars below each trace. Neither ISO nor $1 S, 3 S$-ACPD alone induced lasting changes AHP amplitude or spike frequency adaptation $(t$ test, $p>0.05 ; n=5$ and 6 for ISO and $1 S, 3 S$-ACPD, respectively). Coapplication of ISO plus $1 S, 3 S$-ACPD induced a lasting decrease in AHP amplitude ( $l$ test, $p<0.005 ; n=7$ ) that was associated with blockade of spike frequency adaptation. In cells treated with $1 \mu \mathrm{M}$ staurosporine, coapplication of ISO plus $1 S, 3 S$-ACPD did not induce the lasting decrease in AHP amplitude or a persistent blockade of spike frequency adaptation $(p>0.05 ; n=5)$.
cAMP levels could lead to a lasting increase in cell excitability that persists after cAMP levels return to baseline. Thus, we measured the cAMP response to ISO (100 nM), $1 S, 3 S$-ACPD $(100 \mu \mathrm{M})$, and a combination of the two drugs under the following different agonist incubation protocols: (1) after a $10 \mathrm{~min}$ agonist incubation, (2) after a $40 \mathrm{~min}$ agonist incubation, and (3) after a $10 \mathrm{~min}$ agonist incubation followed by a $30 \mathrm{~min}$ washout of the drugs. As previously reported (Winder and Conn, 1993), ISO, 1S,3S-ACPD, and ISO plus $1 S, 3 S-A C P D$ induced significant increases in CAMP accumulation in hippocampal slices, with the effect of ISO plus $1 S, 3 S$-ACPD being much greater than the predicted additive response to these two compounds (Fig. 6). However, when the drugs were washed from the slices after the $10 \mathrm{~min}$ agonist incubation, cAMP levels returned to basal within $30 \mathrm{~min}$ of drug washout. If the slices were incubated with agonists for the full $40 \mathrm{~min}$, cAMP levels remained elevated for the duration of the experiment (Fig. 6). This suggests that the slices were capable of maintaining an increase in ${ }^{3} \mathrm{H}$-cAMP levels for the duration of the experiment. Thus, it appears that a transient, large increase in cAMP results in a long-lasting increase in the excitability of $\mathrm{CAl}$ pyramidal cells that persists long after cAMP levels have returned to basal.

\section{Discussion}

Long-lasting changes in neuronal excitability and synaptic function that persist after a brief initiating stimulus are likely to play important roles in a wide varicty of lasting changes in animal behavior, including such processes as learning and memory. Thus, much effort has been focused on determining the cellular mechanisms involved in induction and maintenance of persistent forms of synaptic plasticity. Increasing evidence suggests that mGluRs play an important role in a variety of lasting forms of synaptic plasticity in mammalian brain. These include induction of LTP (Collingridge, 1992; Zheng and Gallagher, 1992; Bashir et al., 1993), long-term depression (Stanton et al., 1991), developmental plasticity (Nicoletti et al., 1986; Dudek and Bear, 1989; Boss et al., 1992), and a persistent reduction in synaptic inhibition in rabbit (Liu et al., 1993), but not rat (see Desai and Conn, 1991; Pacelli and Kelso, 1991) hippocampus. We now report that $\mathrm{mGluRs}$ play an important role in a novel associative form of persistent synaptic plasticity in rat hippocampus.

In studying the cellular mechanisms involved in synaptic plasticity, special attention has been focused on forms of synaptic plasticity that are induced by simultaneous activity of two independent inputs to a cell or population of cells, since such associative forms of synaptic plasticity may play an important role in associative learning. In the present studies, we found that coactivation of $\mathrm{mGluRs}$ and $\beta$-adrenergic receptors induces a synergistic increase in cAMP accumulation in hippocampal slices and a lasting potentiation of evoked population spikes in hippocampal area CA1. This is the first demonstration of a physiological role for the $\mathrm{mGluR}$ subtype that potentiates CAMP responses to activation of Gs-coupled receptors, and may represent a novel mechanism for an associative form synaptic plasticity in mammalian brain. Cells in area CA1 receive glutamatergic afferents from within the hippocampus and a major noradrenergic projection from the locus coeruleus (Loy et al., 1980). It is possible that simultaneous activity through these glutamatergic and noradrenergic afferents elicits a synergistic increase in cAMP accumulation and synaptic responses in area CAl similar to that reported here.

Previous studies have shown that maximal activation of $\beta$-adrenergic receptors with high concentrations of ISO can produce a qualitatively similar long-lasting increase in population spike amplitude in area CAl (Heginbotham and Dunwiddie, 1991). However, it is interesting to note that the endogenous agonist of adrenergic receptors, norepinephrine, does not itself produce potentiation of population spikes in area CAl unless norepinephrine is applied in the presence of the $\alpha$-antagonist phentolamine (Mueller et al., 1981). These same studies showed that 


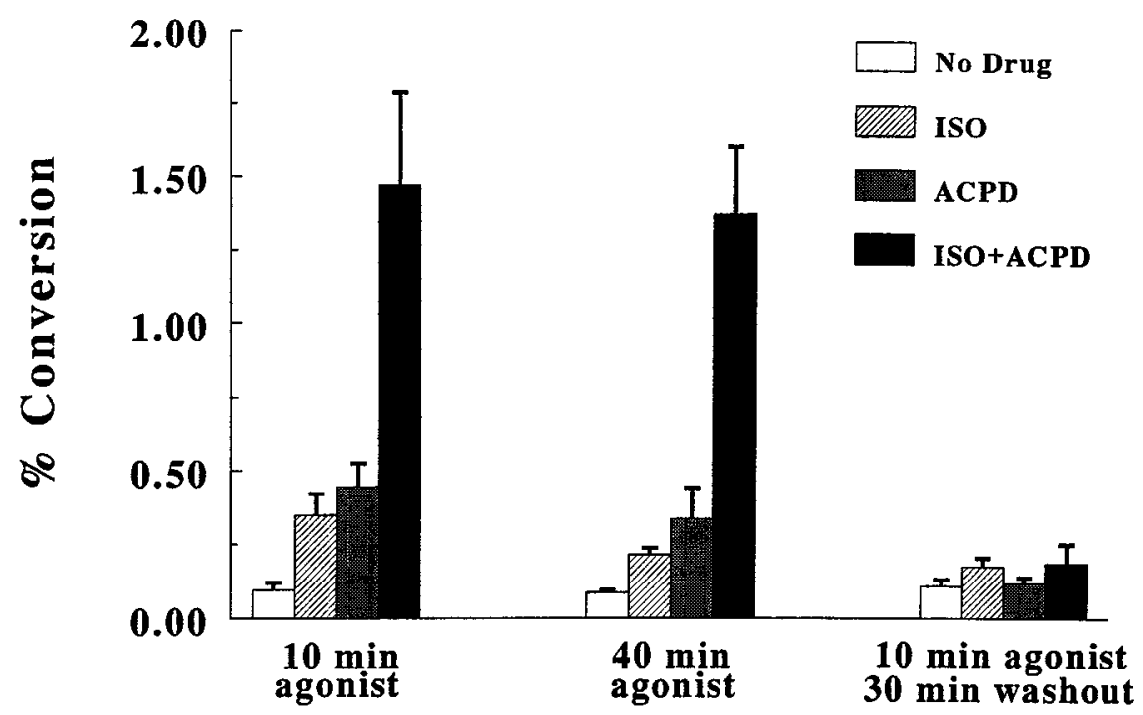

Figure 6. Coactivation of mGluRs and $\beta$-adrenergic receptors does not induce a persistent increase in cAMP. The effects of a 10 min application of ISO (100 nM), 1S,3S-ACPD $(100 \mu \mathrm{M})$, and a combination of the two drugs was tested on cAMP accumulation in hippocampal slices. The group labeled 10 min agonist was exposed to the drugs for $10 \mathrm{~min}$ and the reaction was immediately stopped. The 40 min agonist group was exposed to agonists for $40 \mathrm{~min}$ and the reaction stopped. The 10 min agonist 30 min washout group was exposed to agonists for 10 min, at which point the drugs were washed from the medium, and the tissue incubated in buffer for another $30 \mathrm{~min}$, after which the reaction was terminated. Data are presented as the percentage conversion of ${ }^{3} \mathrm{H}$-adenine to ${ }^{3} \mathrm{H}$-cAMP, and represent the mean \pm SEM of three experiments, each done in triplicate. ISO alone, $1 S, 3 S$-ACPD alone, and ISO plus $1 S, 3 S$-ACPD induced cAMP accumulations that were significantly greater than basal in the 10 min agonist group and the 40 min agonist group (ANOVA, $p<0.05$ ), but not significantly different from basal in the " 10 min agonist 30 min washout" group (ANOVA, $p>0.1$ ).

in the presence of the $\beta$-antagonist timolol, norepinephrine caused depression of population spikes, as does the $\alpha$-agonist clonidine when added alone. Thus, the opposing actions of $\alpha 2$ - and $\beta$-adrenergic receptors activated by norepinephrine likely result in a cAMP response in CAl pyramidal cells that is insufficient to induce a lasting change in cell excitability. Therefore, activation of noradrenergic inputs to CAl may not induce large enough increases in cAMP in pyramidal cells to result in a persistent increase on population spikes. However, if glutamatergic afferents are activated simultaneously, this could potentiate the $\beta$-receptor-mediated cAMP response, and lead to population spike potentiation.

Coactivation of mGluRs and $\beta$-adrenergic receptors could result in lasting increases in $\mathrm{CA} 1$ pyramidal cell excitability by inducing a persistent increase in cAMP levels. Alternatively, a transient increase in cAMP could result in lasting change in excitability of these cells. The data presented here suggest that a transient increase in intracellular cAMP leads to an increase in the excitability of CA 1 pyramidal cells that persists long after cAMP levels have returned to baseline. These findings are reminiscent of a form of synaptic plasticity in Aplysia sensory neurons, in which a transient increase in cAMP leads to persistent activation of cAMP-dependent protein kinase (Sweatt and Kandel, 1989; Bergold et al., 1992).

The mechanism involved in the enhancement of evoked population spikes by coactivation of $\mathrm{mGluRs}$ and $\beta$-adrenergic receptors is clearly distinct from the mechanisms involved in induction of hippocampal LTP in that the increase in population spike amplitude is not accompanied by an increase in transmission at the Schaffer collateral-CA1 synapse. Furthermore, coapplication of ISO and $1 S, 3 S$-ACPD does not induce a lasting reduction of evoked IPSPs recorded in CA1 pyramidal cells, suggesting that the increase in population spike amplitude is not mediated by a persistent disinhibition. However, coapplication of ISO plus $1 S, 3 S$-ACPD induces a persistent depolarization of CA 1 pyramidal cells that is accompanied by a slight increase in input resistance. Both of these effects are likely to increase the number of cells firing an action potential in response to afferent stimulation and thereby contribute to the population spike enhancement. It is interesting to note that NMDA receptor activation can also increase cAMP accumulation in area CA1 (Chetkovich et al., 1991). If NMDA receptor-mediated increases in cAMP levels induce a persistent depolarization of CAl pyramidal cells, this could contribute to the increase in EPSP-population spike coupling that occurs with LTP.

In addition to inducing a lasting depolarization of pyramidal cells, coapplication of ISO and ACPD leads to a long-lasting reduction in the slow AHP that follows a burst of action potentials and a lasting blockade of spike frequency adaptation. The calcium-dependent potassium current that underlies the slow AHP $\left(I_{\mathrm{AHP}}\right)$ is not activated by a single action potential but is thought to be activated by repetitive cell firing (Madison and Nicoll, 1984). Thus, reduction of this current is not likely to contribute to the potentiation of evoked population spikes. However, reduction of the AHP and spike frequency adaptation could play an important role in the overall physiological effects of coactivation of mGluRs and $\beta$-adrenergic receptors and could markedly potentiate responses of CA 1 pyramidal cells to a sustained barrage of excitatory synaptic activity that could lead to repetitive firing.

Previous studies suggest that the effects of ISO plus $1 S, 3 S$ ACPD described here can be mimicked by other manipulations that would be expected to lead to activation of cAMP-dependent protein kinase. Either cell-permeable cAMP analogs or the adenylyl cyclase activator forskolin elicits a long-lasting enhancement of evoked population spikes in area CAl with an accompanying persistent depolarization of CAl pyramidal cells and blockade of the slow AHP and spike frequency adaptation (Dun- 
widdie et al,, 1992). These previous studies, taken together with the present findings that coapplication of ISO plus $1 S, 3 S$-ACPD induces a synergistic increase in CAMP accumulation and that the effects of coapplication of these drugs are blocked by the protein kinase inhibitor staurosporine, are consistent with the hypothesis that these effects are mediated by increases in cAMP levels and activation of CAMP-dependent protein kinase. However, it is interesting to note that cAMP has physiological effects in area CAl that are not seen with coapplication of ISO and $1 S, 3 S$-ACPD. For instance, in addition to increasing CA1 pyramidal cell excitability, forskolin enhances transmission at the Schaffer collateral-CAl synapse (Chavez-Noriega and Stevens, 1992). Similar effects have been seen with vasoactive intestinal polypeptide (VIP; Haas and Gahwiler, 1992), a peptide that increases cAMP accumulation in hippocampal slices. Thus, cAMP may have a variety of effects in area CAl that would potentiate overall transmission through the hippocampal circuit. The exact cAMP-mediated effects of a receptor agonist would depend on the cellular and subcellular localization of the receptors involved. It is possible that the $\beta$-adrenergic receptors involved in the response described here are localized postsynaptically on CA1 pyramidal cells, whereas VIP receptors may be localized on Schaffer collateral terminals. However, it is interesting to note that mGluR activation enhances cAMP responses to all agonists that have been studied to date, including VIP (Winder and Conn, 1992; Winder et al., 1993). Under normal physiological conditions, the exact effects of mGluR activation in area CAl may depend, in part, on what other afferents to this area are active. In future studies it will be important to determine the effect of $1 S, 3 S$-ACPD on physiological responses to agonists that potentiate population spikes by a different mechanism than that of $\beta$-adrenergic receptor agonists. Furthermore, future studies should be aimed at determining if the potentiative cAMP response and increase in CA1 pyramidal cell excitability occurs in response to simultaneous activation of Schaffer collaterals and locus coeruleus afferents to area CA1.

\section{References}

Bashir ZI, Bortolotto ZA, Davies CH, Berretta N, Irving AJ, Seal AJ, Henley JM, Jane DE, Watkins JC, Collingridge GL (1993) Induction of LTP in the hippocampus needs synaptic activation of glutamate metabotropic receptors. Nature 363:347-350.

Baskys A, Malenka RC (1991) Agonists at metabotropic glutamate receptors presynaptically inhibit EPSCs in neonatal rat hippocampus. J Physiol (Lond) 444:687-701.

Bergold PJ, Beushausen SA, Sacktor TC, Cheley S, Bayley H, Schwartz JH (1992) A regulatory subunit of the cAMP-dependent protein kinasc down-regulated in Aplysia sensory neurons during long-term sensitization. Neuron 8:387-397.

Blanton MG, LeTurco JJ, Kriegstein AR (1989) Whole-cell recording from neurons in slices of reptilian and mammalian cerebral cortex. J Neurosci Methods 30:203-210.

Bliss TVP, Collingridge GL (1993) A synaptic model of memory: longterm potentiation in the hippocampus. Nature 361:31-39.

Bortolotto ZA, Collingridge GL (1992) Activation of metabotropic receptors induces long-term potentiation. Eur J Pharmacol 214:297298.

Boss VB, Desai MA, Smith TS, Conn PJ (1992) Trans-ACPD-induced phosphoinositide hydrolysis and modulation of hippocampal pyramidal cell excitability do not undergo parallel developmental regulation. Brain Res 594:181-188.

Chavez-Noriega LE, Stevens CF (1992) Modulation of synaptic efficacy in field $\mathrm{CA} 1$ of the rat hippocampus by forskolin. Brain Res 574: 85-92.

Chetkovich DM, Gray R, Johnston D, Sweatt JD (1991) $N$-methyl$D$-aspartate receptor activation increases cAMP levels and voltage- gated $\mathrm{Ca}^{2+}$ channel activity in area $\mathrm{CAl}$ of hippocampus. Proc Natl Acad Sci USA 88:6467-6471.

Collingridge GL (1992) The mechanism of induction of NMDA receptor-dependent long-term potentiation in the hippocampus. Exp Physiol 77:771-797.

Collins DR, Davies SN (1993) Co-administration of $(1 S, 3 R)-1$-aminocyclopentane-1,3-dicarboxylic acid and arachidonic acid potentiates synaptic transmission in rat hippocampal slices. Eur $\mathbf{J}$ Pharmacol 240:325-326.

Davis PD, Hill CH, Keech E, Lawton G, Nixon JS, Sedgwick AD, Wadsworth J, Westmacott D, Wilkinson SE (1989) Potent selective inhibitors of protein kinase C. FEBS Lett 259:61-63.

Desai MA, Conn PJ (1990) Selective activation of phosphoinositide hydrolysis by a rigid analogue of glutamate. Neurosci Lett 109:157162.

Desai MA, Conn PJ (1991) Excitatory effects of ACPD receptor activation in the hippocampus are mediated by direct effects on pyramidal cells and blockade of synaptic inhibition. $J$ Neurophysiol 66: 40-52.

Desai MA, Smith TS, Conn PJ (1992) Multiple metabotropic glutamate receptors regulate hippocampal function. Synapse 12:206-213.

Dudek SM, Bear MF (1989) A biochemical correlate of the critical period for synaptic modification in the visual cortex. Science 246: 673-675.

Dunwiddie TV, Taylor M, Heginbotham LR, Proctor WR (1992) Longterm increases in excitability in the CAl region of rat hippocampus induced by $\beta$-adrenergic stimulation: possible mediation by $\mathrm{cAMP}$. J Neurosci 12:506-517.

Garbarg M, Schwartz J-C (1988) Synergism between histamine H1and $\mathrm{H} 2$-receptors in the cAMP response in guinea pig brain slices: effects of phorbol esters and calcium. Mol Pharmacol 33:36-43.

Haas HL, Gahwiler BH (1992) Vasoactive intestinal polypeptide modulates neuronal excitability in hippocampal slices of the rat. Neuroscience 47:273-277.

Heginbotham LR, Dunwiddie TV (1991) Long-term increases in the evoked population spike in the CAl region of rat hippocampus induced by $\beta$-adrenergic receptor activation. J Neurosci 11:2519-2527.

Johnson RD, Minneman KP (1986) Characterization of $\alpha \mathrm{l}$-adrenoreceptors which increase cyclic AMP accumulation in rat cerebral cortex. Eur J Pharmacol 129:293-305.

Johnson RD, Minneman KP (1987) Differentiation of $\alpha 1$-adrenergic receptors linked to phosphatidylinositol turnover and cAMP accumulation in rat brain. Mol Pharmacol 31:239-246.

Liu Y-B, Disterhoft JF, Slater NT (1993) Activation of metabotropic glutamate receptors induces long-term depression of GABAergic inhibition in hippocampus. J Neurophysiol 69:1000-1004.

Loy R, Koziell DA, Lindsey JD, Moore RY (1980) Noradrenergic innervation of the adult rat hippocampal formation. J Comp Neurol 189:699-710.

Madison DV, Nicoll RA (1984) Control of the repetitive discharge of rat CA1 pyramidal neurones in vitro. J Physiol (Lond) 354:319-331.

Madison DV, Nicoll RA (1986) Actions of noradrenaline recorded intracellularly in rat hippocampal CAl pyramidal neurones, in vitro. J Physiol (Lond) 372:221-244

Magistretti PJ, Schorderet M (1985) Norepinephrine and histamine potentiate the increases in cyclic adenosine $3^{\prime}: 5^{\prime}$-monophosphate elicited by vasoactive intestinal polypeptide in mouse cerebral cortical slices: mediation by $\alpha 1$-adrenergic and $\mathrm{H} 1$-histaminergic receptors. J Neurosci 5:362-368.

Mueller AL, Hoffer BJ, Dunwiddic TV (1981) Noradrenergic responses in rat hippocampus: evidence for mediation by $\alpha$ and $\beta$ receptors in the in vitro slice. Brain Res 214:113-126.

Nicoletti F, Iadarola MF, Wroblewski JT, Costa E (1986) Excitatory amino acid recognition sites coupled with inositol phospholipid metabolism: developmental changes and interaction with $\alpha 1$-adrenoreceptors. Proc Natl Acad Sci USA 83:1931-1935.

Otani S, Ben-Ari Y (1991) Metabotropic receptor-mediated long-term potentiation in rat hippocampal slices. Eur J Pharmacol 205:325326.

Pacelli GJ, Kelso SR (1991) Trans-ACPD reduces multiple components of synaptic transmission in the rat hippocampus. Neurosci Lett $132: 267-269$.

Pilc A, Enna SJ (1986) Activation of $\alpha 2$-adrenergic receptors augments neurotransmitter-stimulated cyclic AMP accumulation in rat brain cerebral cortical slices. J Pharmacol Exp Ther 237:725-730. 
Schaad NC, Schorderet M, Magistretti PJ (1989) Accumulation of cyclic AMP elicited by vasoactive intestinal peptide is potentiated by noradrenaline, histamine, adenosine, baclofen, phorbol esters, and ouabain in mouse cerebral cortical slices: studies on the role of arachadonic acid metabolites and protein kinase C. J Neurochem 53: 1941-1951.

Schoepp DD, Conn PJ (1993) Metabotropic glutamate receptors in brain function and pathology. Trends Pharmacol Sci 14:13-20.

Shimizu H, Crevelling CR, Daly JW (1969) A radioisotopic method for measuring the formation of adenosine $3^{\prime}, 5^{\prime}$-cyclic monophosphate in incubated slices in brain. J Neurochem 16:1609-1619.

Slack JR, Pockett S (1991) Cyclic AMP induces long-term increase in synaptic efficacy in CA1 region of rat hippocampus. Neurosci Lett 130:69-72.

Stanton PK, Chattarji S, Sejnowski TJ (1991) 2-Amino-3-phosphonopropionic acid, an inhibitor of glutamate-stimulated phosphoinositide turnover, blocks induction of homosynaptic long-term depression, but not potentiation, in rat hippocampus. Neurosci Lett 127: 61-62.
Sweatt JD, Kandel FR (1989) Persistent and transcriptionally-dependent increase in protein phosphorylation in long-term facilitation of Aplysia sensory neurons. Nature 339:51-54.

Winder DG, Conn PJ (1992) Activation of metabotropic glutamatc receptors in the hippocampus increases cyclic AMP accumulation. J Neurochem 59:375-378.

Winder DG, Conn PJ (1993) Activation of metabotropic glutamate receptors increases cAMP accumulation in hippocampus by potentiating responses to endogenous adenosine. J Neurosci 13:38-44.

Winder DG, Smith TS, Conn PJ (1993) Pharmacological differentiation of metabotropic glutamate receptors coupled to potentiation of cAMP responses and phosphoinositide hydrolysis. J Pharmacol Exp Ther 266:518-525.

Zheng F, Gallagher JP (1992) Metabotropic glutamate receptors are required for the induction of long-term potentiation. Neuron $9: 163$ 172. 